\title{
Analysis of thermal ageing effect (hold time - crystallinity rate - mechanical property) on high density polyethylene (HDPE)
}

\author{
Rabah Ferhoum*, Meziane Aberkane, Mohand Ould ouali, Kamel Hachour \\ ${ }^{1}$ Laboratoire Elaboration et Caractérisation des Matériaux et Modélisation, université Mouloud MAMMERI de Tizi-Ouzou, Algeria
}

Email address:

ferhoum@yahoo.fr(R. Ferhoum), aberkane@yahoo.fr(M. Aberkane), oudouali_m@yahoo.fr(M. O. ouali), hachour_k@yahoo.fr(K. Hachour)

\section{To cite this article:}

Rabah Ferhoum, Meziane Aberkane, Mohand Ould ouali, Kamel Hachour. Analysis of Thermal Ageing Effect (Hold Time - Crystallinity Rate - Mechanical Property) on High Density Polyethylene (HDPE). International Journal of Materials Science and Applications. Vol. 2, No. 3, 2013, pp. 109-114. doi: 10.11648/j.ijmsa.20130203.17

\begin{abstract}
This work is devoted to the experimental study of thermal ageing effect on the large deformation stress-strain behaviour of PE100, tensions tests are conducted on this material samples submitted to a temperature of $90^{\circ} \mathrm{C}$ during different hold times. It is found that thermal ageing causes an increase of all properties measured, including crystallinity, melting temperature, Young Modulus, yield stress and stress at break. We show, by different investigation techniques like X-rays diffraction, Transform Infrared Spectroscopy (FTIR), that increase of mechanical properties is not due to a chemical change but is due to an increase of the crystallinity rate commonly designated by the post-crystallization phenomena. DSC and DMA experiments show secondary crystallization, homogenization of primary crystals and decrease of the amorphous phase mobility.
\end{abstract}

Keywords: Thermal Ageing, HDPE, Finite Strain, Crystallinity

\section{Introduction}

In a practical field, polymer materials have been shown to express some advantages, for instance, light-weight, high-strength, anti-rust, and easy processibility. These advantages are based on comparison with metal and inorganic materials. The specific strength of polymer materials is relatively high and polymer materials do not form colored rust like metal. However, polymer materials degrade under various circumstances such as low and/or high temperature, exposure to rain and/or sunlight, under the water and/or soil. Respectively, various properties of these materials are changed by the degradation due to ultra-violet (UV), radiation, chemical influences, ageing, fatigue, swelling, wet and dry cycle, and complex condition of respective degradation [1-3]. The behaviour of semicrystalline polymers is strongly microstructure and morphology -dependent. Moreover, it varies according to conditions in a process and resulting microstructural conditions. Correlations between crystalline morphology and mechanical properties of polymers have attracted substantial attention in the past [4-7]. Previous studies of structure-property relations focused mainly on structure, whereas mechanical properties remained of secondary importance. In recent work, many authors [8-11] note that after ageing and annealing of many semicrystalline polymers it is observed a change of the microstructure and the morphology of this material expressed by a secondary crystallization and a creation of small-organized volumes in the amorphous phase.

In this work, our goal is to study the effect of the thermal ageing particularly the hold time on the mechanical behaviour of the HDPE. The challenge is to identify the relation between crystallinity rate and mechanical properties by using different techniques like static mechanical measurements, the Fourier transform infrared spectroscopy (FTIR) and the X- rays diffraction. The microstructure, after ageing, of this material, is characterized by the differential scanning calorimetry (DSC) and the dynamic mechanical analysis (DMA). The paper is organized as follows. Section 2 is focused on the experimental investigations and Section 3 is devoted to analysis of the experimental results and to the concluding remarks. 


\section{Material and Experimental Methods}

\subsection{The Studying Material}

The PE100 is a semi-crystalline thermoplastic including an amorphous and crystalline phases. Its molar mass is the order of $300000 \mathrm{~g} / \mathrm{mol}$, the fusion and glass transition temperatures are respectively $135^{\circ} \mathrm{C}$ and $-125^{\circ} \mathrm{C}$.

\subsection{The Thermal Ageing Procedure}

The rectangular shaped samples of dimension 100x15x 6 $\mathrm{mm} 3$ are cut into PE 100 tubes and put inside the steam room under the following conditions:

- The speed of heating is of $5^{\circ} \mathrm{C} / \mathrm{min}$

- The samples are maintaining during different times 48h, 96h, 144h, $192 \mathrm{~h}$ at $90{ }^{\circ} \mathrm{C}$ and cooling in a steam room.

\subsection{Mechanical Study}

The stress- train behavior of HDPE before and after thermal ageing effect is characterized under uniaxial tension on an electromechanical testing machine. The local strain was measured using a video-controlled system (VideoTraction) consisting of a CCD camera interfaced with a computer. One of the main advantages of the VideoTraction method is its ability to keep the local true train-rate constant $[13,14]$. This technique is based on the follow-up of four (4) markers printed on the front surface of the sample, where two among them are aligned along the tensile direction and the two other according to the transverse direction 2 (figure 1). The data acquisition system automatically records the true tress versus the true train, using the initial sample dimensions and assuming incompressibility. The experiments are achieved at the same temperature but under a single local true train rate of $10^{-3} \mathrm{~s}^{-1}$.

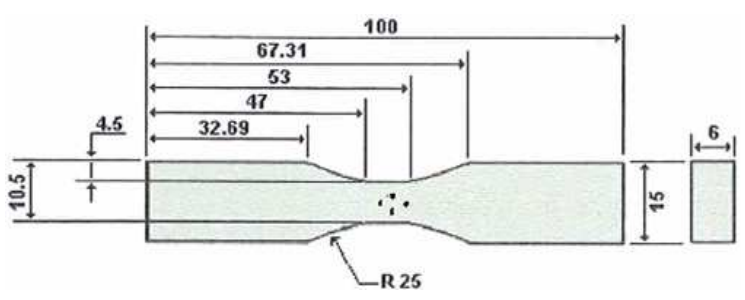

Figure 1. Geometry of tensile sample (dimension in $\mathrm{mm}$ )

\subsection{Differential Scanning Calorimetry (DSC)}

DSC characterizes polymer phase transformations, particularly the melting of the crystalline part. Enthalpy variations versus the time and temperature are obtained from DSC during controlled heating for five (05) samples before and after ageing. A PerkinElmer DSC Pyris (Waltham, MA) is used with a temperature ramp of $10^{\circ} \mathrm{C} / \mathrm{min}$ from 70 to $200^{\circ} \mathrm{C}$. A mass of $1.300 \mathrm{mg}$ is chosen, and precautions were taken to ensure a stable sample specific surface to keep a constant thermal transfer coefficient. Melting temperature is detected as the peak temperature of the main endotherm by the programme. Crystallinity is derived from ratio of the measured heat of fusion of polyethylene to heat of fusion for finite crystals, acquired from the

$$
\chi=\frac{\Delta H}{\Delta H_{100 \%}}
$$

where $\Delta \mathrm{H}$ is the sample melting enthalpy (corresponding to the melting peak area), $\Delta H_{100 \%}$ the full crystalline sample melting enthalpy (290 J/g by Wunderlich [12]).

\subsection{Dynamic Mechanical Analysis (DMA)}

Dynamic mechanical analysis (DMA) is performed to provide information both on the mechanical relaxations and on the mechanical properties at small strains. DMA provides the complex modulus versus the temperature and allows the study of the mechanical relaxations. Parallel-piped samples $(30 \mathrm{~mm} \times 3 \mathrm{~mm} \times 1 \mathrm{~mm})$ were tested in a torsion pendulum as a function of temperature. A frequency of $1 \mathrm{~Hz}$ and a heating rate of $1^{\circ} \mathrm{C} / \mathrm{min}$ were used.

\section{Experimental Results and Discussions}

\subsection{Effect of Thermal Ageing on the Mechanical Behavior}

True stress versus true strain graph shows, three domains of deformations. At the beginning, the material shows an elastic expansion related to Poisson's ratio of the material, which is followed by a slight contraction when the material enters the plastic domain near the yield stress, during stretching, plastic compaction (contracting volume strain for intermediate stretching ratio) is in competition with dilatation in the control of volume change. The compaction phenomenon is magnified when the mobility of the amorphous chains and the time to accommodate macroscopic deformation are favoured. In higher strains, the final hardening stage is occurred in HDPE and homogenous stretching or local necking occurs with visible whitening of the samples, resulting from the crazes formation in the amorphous layers between crystalline lamellae. These phenomena cause an important dilatation of polymers under tension (figure $2 \mathrm{a}$ and $\mathrm{b}$ ). This large dilatation is partly due to the transformation of the initial spherulitic order into fiber-type morphology, and partly to cavitations process in the material.

In figure 3 the stress - strain curves of HDPE stretched up to failure before and after thermal ageing are shown. In this figure, we observe that most of the tensile properties of HDPE are affected by thermal ageing. Indeed, significant changes in elastic modulus, yield stress and strain at break are noted. We observe, particularly, that yield stress and stress at break increase with thermal ageing. We note a drop of the yield stress from its initial value of $24 \mathrm{MPa}$ before ageing to a value of $36 \mathrm{MPa}$ after ageing during $96 \mathrm{~h}$ at $90^{\circ} \mathrm{C}$. 

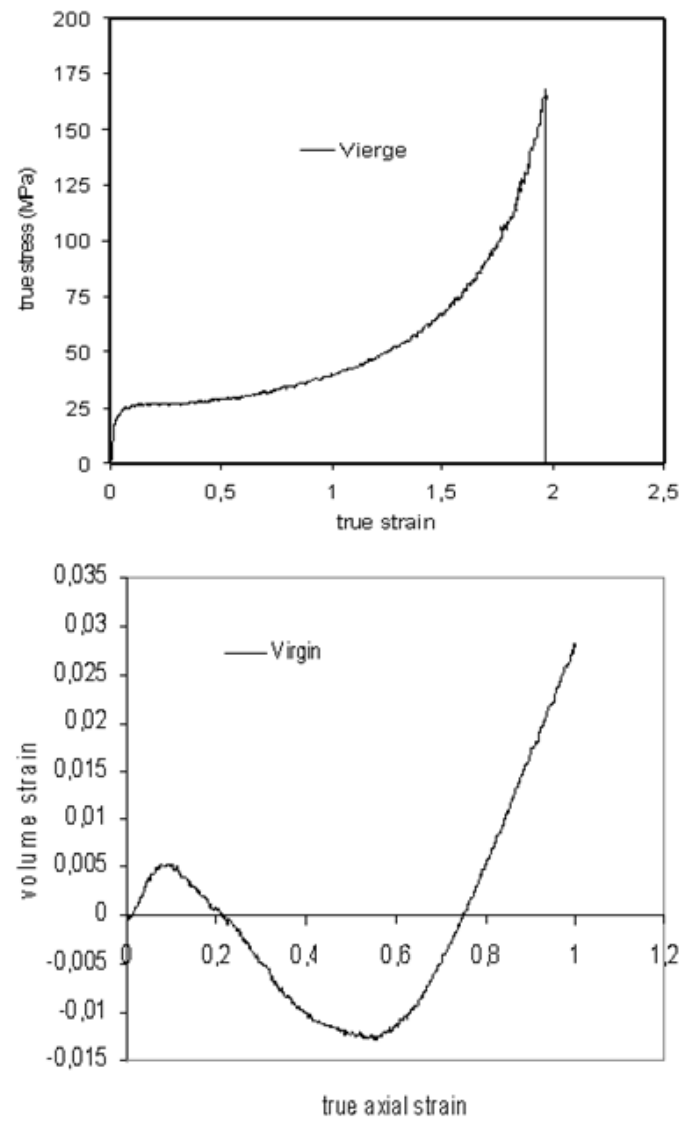

Figure 2. (a) Mechanical behaviour of virgin PE100 (true axial stress - true axial strain), (b) Volume strain of HDPE as a function of true strain

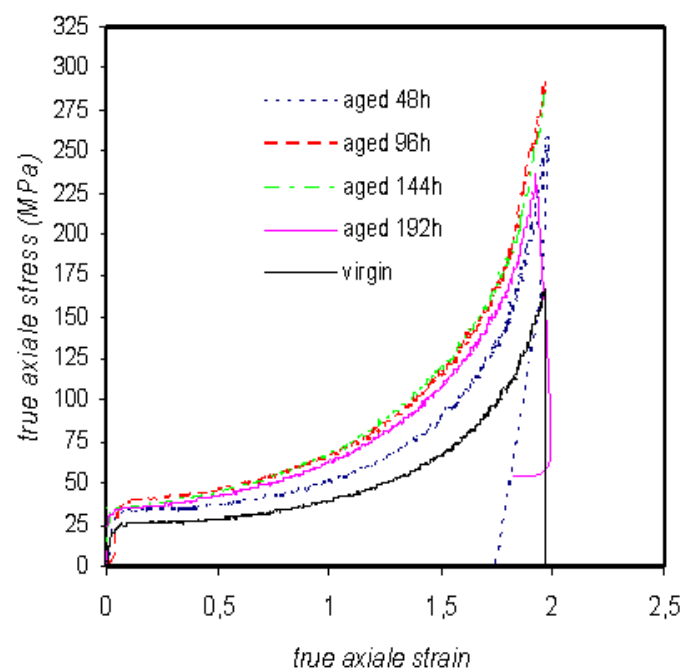

Figure 3. Thermal ageing effect on mechanical behaviour of PE100 (true axial stress - true axial strain)

Figure 4 shows the dependence of volume strain on axial strain. We note, in this figure, a rapid increase of volume strain for the HDPE aged to $144 \mathrm{~h}$. This increase is, probably, due to the formation and the growth of cavities. The formation of these cavities is favoured in the case where the rate of crystallinity is important. This tendency is not the same for all the specimens tested. In the virgin HDPE, the dilatation is not important because the preferred way of plastic strain is lamellae sliding and crystallographic slips initiated at yield [15].

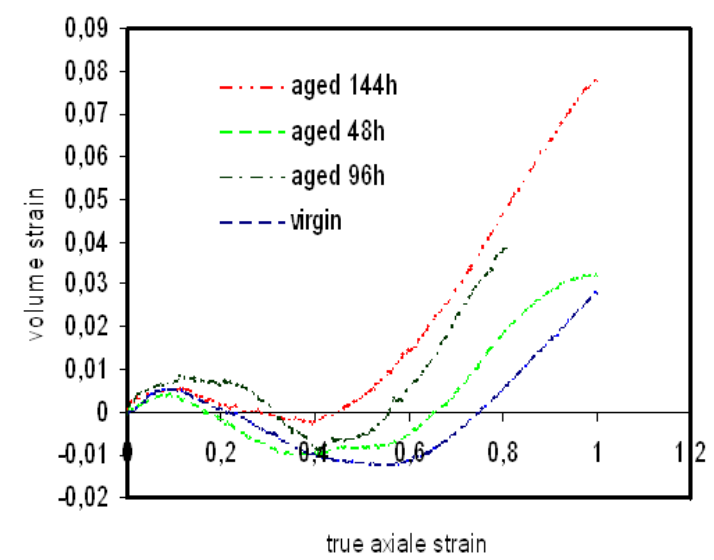

Figure 4. Effect of thermal ageing on the volume strain-axial strain curve of PE 100

\subsection{Microstructure Characterization by Fourier Transform Infrared Spectroscopy (FTIR)}

The Fourier Transform Infrared Spectroscopy (FTIR) technique confirms that no supplementary chemical link is produced (Fig.5). We note that the intensity of transmittance peaks of the $\mathrm{C}=\mathrm{C}$ links and $\mathrm{C}-\mathrm{H}$ are not influenced by the ageing treatment. The specimens remains unaltered, what confirms that the change of the mechanical behaviour of the PEHD, is not due to the modification of the present chemical groups in the material, but to the phenomenon of structural morphology change that we designates by post-crystallization. We note, also, the existence of group hydroxyl "OH" to the level of the vibration strip to 3500 $1 / \mathrm{cm}$.

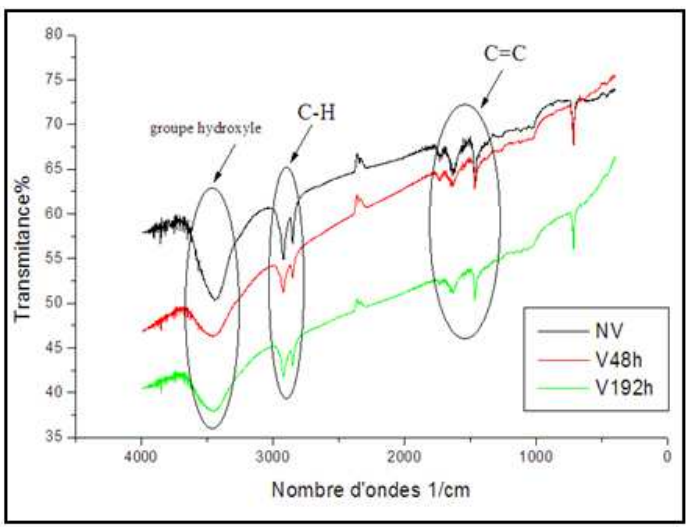

Figure 5. Superposition of the FTIR specters of the samples (virgin, aged $48 h$, aged 192h)

\subsection{Analysis by X-Rays Diffraction}

The figures 6,7 and 8 present the set of the diffractogrammes gotten by diffraction of the X-rays of three samples (virgin, aged $48 \mathrm{~h}$, aged $192 \mathrm{~h}$ ). We note that two representative peaks of the quantity of diffracting matter characterize the specters. As we also note that, the peaks nearly diffract to identical angles, but with different 
intensities. This result is in good agreement with the FTIR analysis that shows the absence of degradation of HDPE.

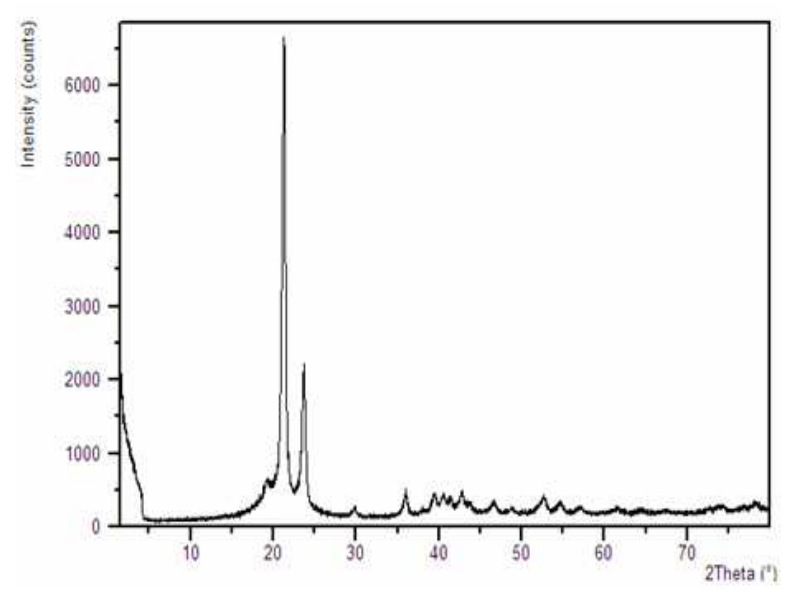

Figure 6. diffractogramme of the virgin sample.

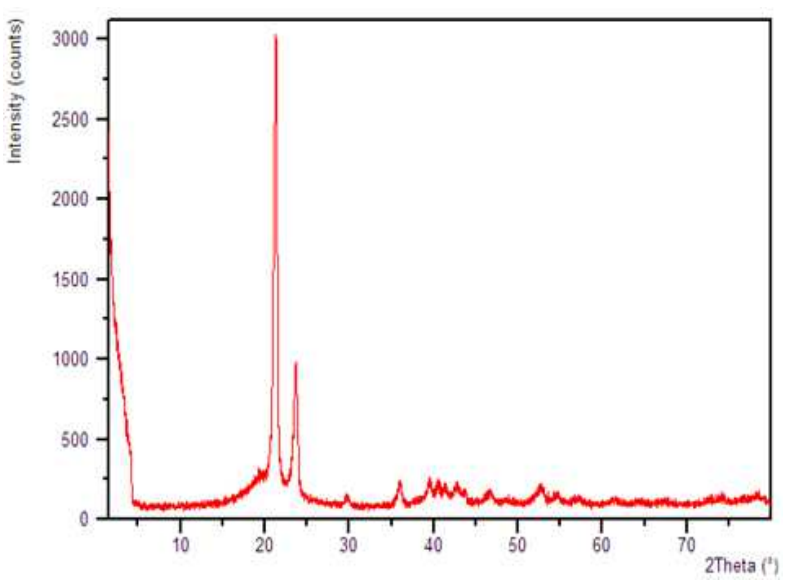

Figure 7. diffractogramme of the sample aged $48 \mathrm{~h}$.

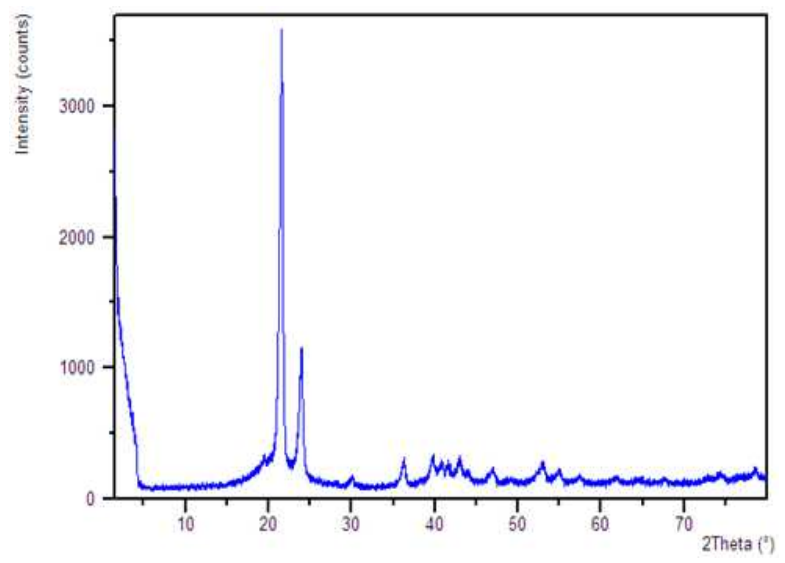

Figure 8. XRD Patherms of the sample aged $192 \mathrm{~h}$

Table (1) summarizes the result of calculation of the complete width and the width in mid-height. We observe, in this table, a diminution of the intensity peaks in mid-height for the two aged samples compared to the reference one (virgin samples). This confirms an increase of the crystallinity degrees of the PEHD
Table 1. The calculation results of the complete width and the width at the mid-height

\begin{tabular}{lcc}
\hline samples & Complete width & Width to mid height \\
\hline virgin & 0.1980 & 0.2007 \\
Aged 48h & 0.0660 & 0.0669 \\
Aged 192h & 0.1815 & 0.1840 \\
\hline
\end{tabular}

\subsection{Microstructure Characterization (DSC)}

Melting temperature $\left({ }^{T_{m}}\right)$ and degree of crystallinity (D.C.) of both virgin polyethylene and aged one at $90{ }^{\circ} \mathrm{C}$ for various hold time obtained by DSC are displayed in Fig. 9 and 10. We see that both $T_{m}$ and D.C increased with increasing of the hold time, and stabilization occur after 144 $\mathrm{h}$ (table 2).

Table 2. Melting temperatures and crystallinity ratio of virgin and aged at $\left(90^{\circ} \mathrm{C}\right)$ simples corresponding to DSC traces presented in Fig. 12

\begin{tabular}{lccccc}
\hline Samples & Virgin & $\begin{array}{c}\text { Aged } \\
48 \mathrm{~h}\end{array}$ & $\begin{array}{c}\text { Aged } \\
96 \mathrm{~h}\end{array}$ & $\begin{array}{c}\text { Aged } \\
144 \mathrm{~h}\end{array}$ & $\begin{array}{c}\text { Aged } \\
192 \mathrm{~h}\end{array}$ \\
$\Delta H \quad(\mathrm{j} / \mathrm{g})$ & 131,60 & 182,34 & 200,11 & 173,28 & 171,25 \\
$\begin{array}{l}\text { melting peak }\left({ }^{\circ} \mathrm{C}\right) \\
\begin{array}{l}\text { Crystallinity } \\
\text { degrees \% }\end{array}\end{array}$ & 128,69 & 130,15 & 130,96 & 130,75 & 130,31 \\
\hline
\end{tabular}

The shape of the melting peak directly depends on the ageing time. For the virgin sample, the melting temperature defined as the maximum value of the endothermic peak seats at $128,68{ }^{\circ} \mathrm{C}$. This peak is quite asymmetric, with a large distribution towards the lower temperatures. Virgin samples exhibit a rather large distribution of crystallites thickness. After thermal ageing, homogenization goes on. The main melting peak is more symmetrical with a melting temperature of about $130{ }^{\circ} \mathrm{C}$ (Fig.9).

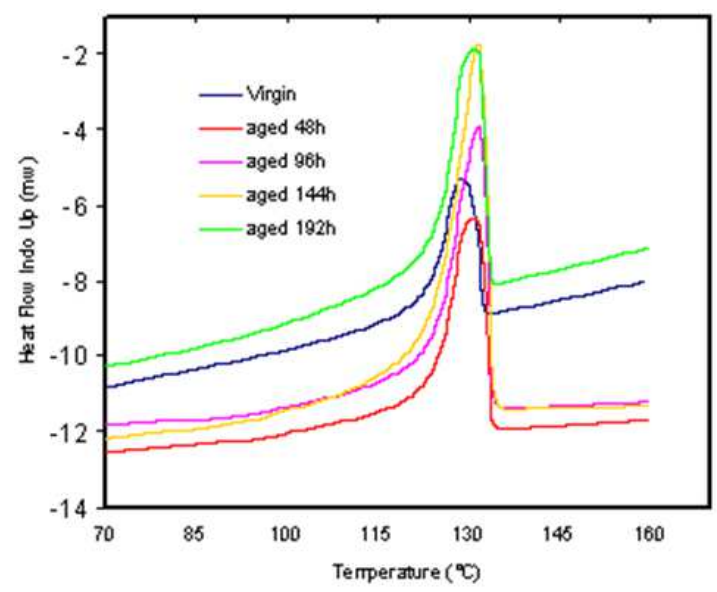

Figure 9. Crystallinity degrees from DSC experiments for different samples.

Fig. 10 shows the comparison of the hold time effect on Young modulus and yield stress value. Although Young modulus and yield stress strength also increased with increasing hold time. A good correlation between the increasing of the young modulus, yield stress and the crystallinity rate is observed. 

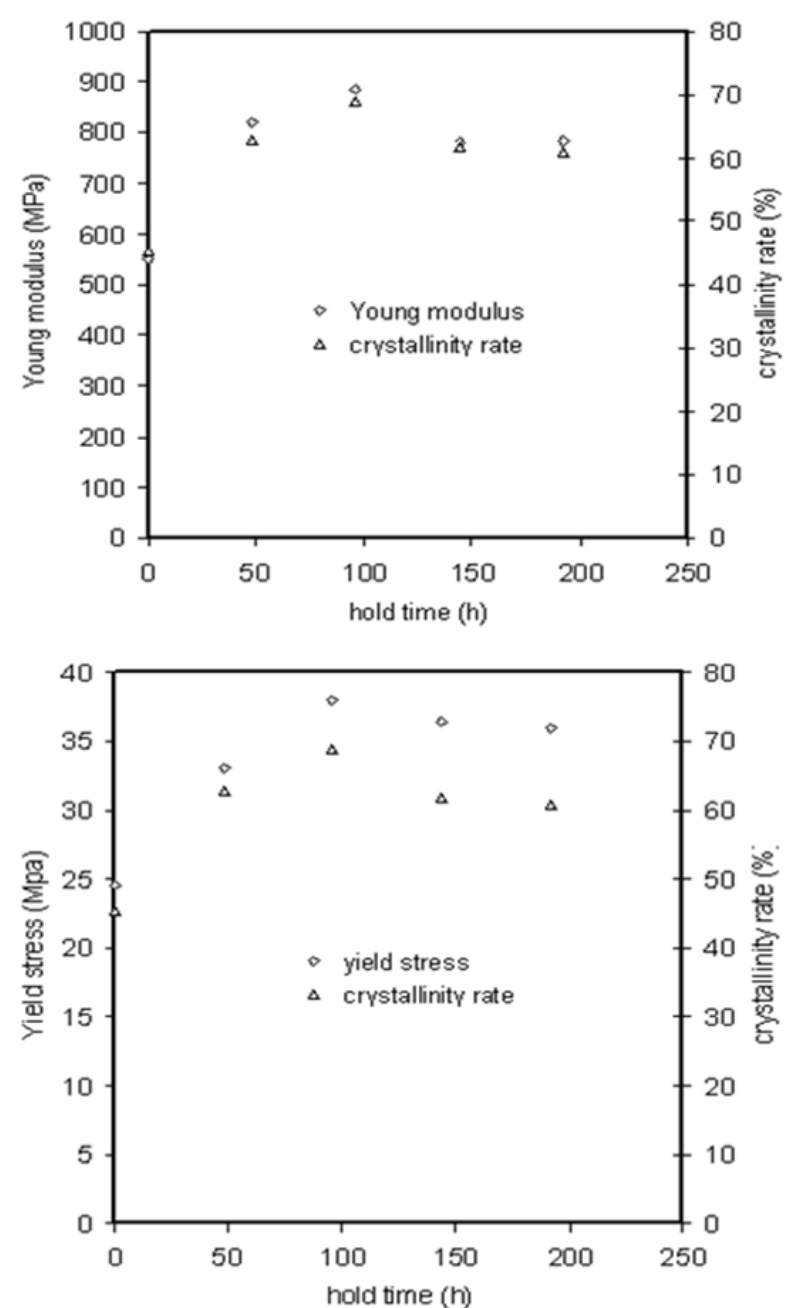

Figure 10. Influence of hold time on Young modulus, yield stress and crystallinity rate and tensile yield strength of high density polyethylene.

The crystallinity ratio increases after thermal ageing at $90^{\circ} \mathrm{C}$ for different times, this result confirmed the X-rays and IRTF analysis

\subsection{Small-Strain Mechanical Characterization (DMA)}

DMA experiments have been performed to evaluate the consequences of thermal ageing effect on the mechanical behaviour of the amorphous phase. The shear modulus, storage modulus and loss angle obtained from DMA experiments in the case of virgin and aged sample at $90{ }^{\circ} \mathrm{C}$ for different times have been plotted versus the temperature in Figure 11. From these figure we observe:

The peak centred at around $-111^{\circ} \mathrm{C}$ for virgin sample and $-109{ }^{\circ} \mathrm{C}$ for aged sample on $\tan \delta$ depicts the glassy transition. A $40 \%$ decrease of the storage modulus is observed at the same time for the virgin sample (fig. 11a).

A small peak on $\tan \delta$ with a maximum at $-30^{\circ} \mathrm{C}$ appears for the virgin sample in Fig. 12 a. This peak is not observed for the sample ageing. El Mohajir and Heymans [16] observed a similar phenomenon in PVDF after annealing $1 \mathrm{~h}$ at $150{ }^{\circ} \mathrm{C}$ and further annealing at temperature lower than $80^{\circ} \mathrm{C}$. It was associated to the upper glassy transition.
Finally, the loss modulus of PE100 aged sample seems lower than that of PE100 virgin, particularly below $0^{\circ} \mathrm{C}$, letting suppose that the viscoelastic character is a little less mark for this one (Fig.11 c).
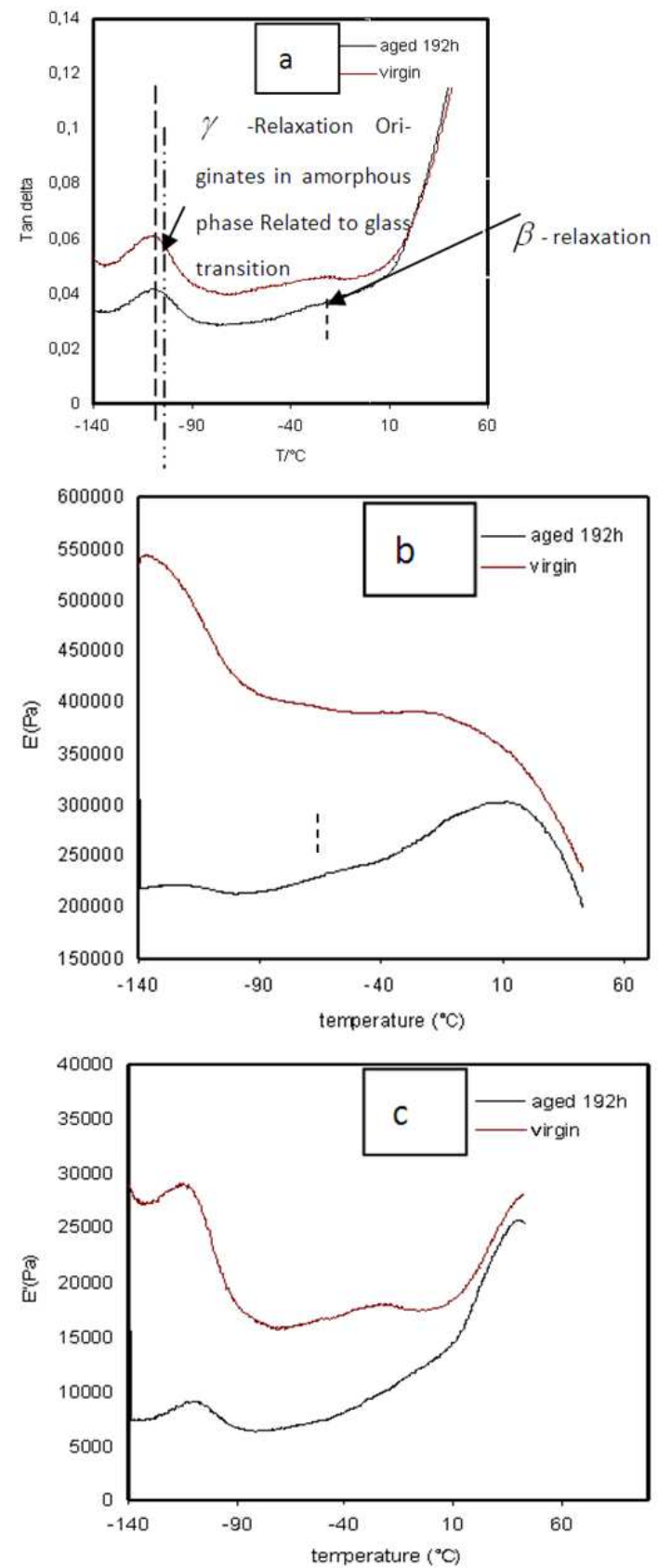

Figure 11. Influence of thermal ageing at $90{ }^{\circ} \mathrm{C}$ from the DMA experiments. (a) tangent delta, (b) storage modulus, (c) loss modulus

The storage modulus is consistent with the evolution of the main melting peak in the DSC experiments. This phenomena is associated to the formation of secondary crystals during ageing at high temperature (Fig.12 b). As a conclusion DSC and DMA experiments point out a size homogenization and a decrease of defects within the main crystallites population and a secondary crystallization and an associated decrease of the amorphous phase mobility. 


\section{Conclusion}

The present work has led to the following conclusions:

- The thermal ageing causes an increase in all properties measured, including crystallinity, melting temperature, Young Modulus, yield stress and stress at break.

- The Fourier Transform Infrared Spectroscopy (FTIR) technique confirms well that no supplementary chemical link is produced

- At low hold time (48h and 96h) the degree of increase in young modulus and yield stress was important but they stabilized at higher hold time (144h and 196h)

- The thermal ageing has an important influence on the true volume strain evolution. We show that the dilation of the true volume strain raises with the increase of crystallinity rate, and this, is probably due to the formation of the cavities which is favoured in the case where the rate of crystallinity is important

- $\quad$ From DMA experiments, we expect an evolution of the morphology of HDPE after thermal ageing, and this is due to:

1. a secondary crystallisation

2. an improvement, thickening and size homogenization of the primary crystals population

3. A decrease of the amorphous phase mobility.

\section{References}

[1] F. Dobinson, J. Preston, New high - temperature polymers. II. Ordered aromatic co polyamides containing fused and multiple ring system. J Polym Sci Part A-1, 1966.

[2] W.F. Hale, A.G. Farnham, R.N. Johnson and R.A.
Clendinning. Poly (aryl ethers) by nucleophilic aromatic substitution. II. Thermal study. J Polym Sci Part A-1 Polym Chem, 1967.

[3] G.G. Cameron, G.P. Kerr, Thermal degradation of polystyrene - I. Chain scission at low temperatures. Eur Polym J, 4:709-17, 1968.

[4] R.A. Bubeck, Mater. Sci. Eng. Rep. 39, 1-28, 2002.

[5] A. Galeski, Prog. Polym. Sci. 28 1643-1699, (2003).

[6] H.E.H.Meijer, L.E. Govaert, Prog. Polym. Sci. 30, 915-938 (2005).

[7] R. Seguela, J. Macromol. Sci. C 45, 263-287 (2005).

[8] L. Hubert, Thesis, Insa-Lyon, France, 2001.

[9] A. Alizadeh, L. Richardson, J. Xu and S. McCartney, Macromolecules 32, 6221-6235, 1999.

[10] H. Marand, A. Alizadeh, R. Farmer, R. Desai and V. Velikov, Macromolecules 33, pp. 3392-3403, 2000.

[11] S.X. Lu, P. Cebe, Polymer 37, 4857-4863, 1996.

[12] K. Nakagawa, Y. Ishida, Polym. Sci., Part B: Polym. Phys. 11, 1503-1533 (1973).

[13] C. G'Sell, J.M. Hiver, A. Dahoun. Experimental characterization of deformation damage in solid polymers under tension, and its interrelation with necking. International Journal of Solids and Structures 39, 3857-3872. 2002

[14] R. Ferhoum, M. Aberkane, M. Ould Ouali. Modelling of thermal ageing effect on elastic-viscoplastic behavior of semi-crystallin polymers by D.N.L.R approach. Procedia Engineering, Volume 10, 2011.

[15] A. Pawlak, Cavitations during tensile deformation of high-density polyethylene. Polym. 48, pp. 1397-1409, 2007.

[16] B. El Mohajir, N. Heymans, Polymer 42, pp.7017-7023, 2001. 